\title{
Metallic Burden of Deciduous Teeth and Childhood Behavioral Deficits
}

\section{Tony J.H. Chan ${ }^{1}$, Carolina Gutierrez ${ }^{2}$ and Oladele A. Ogunseitan ${ }^{1,3, *}$}

1 School of Social Ecology, University of California, Irvine, CA 92697, USA; E-Mail: tonyhp888@gmail.com

2 School of Social Sciences, University of California, Irvine, CA 92697, USA; E-Mail: carolh2ogutierrez@gmail.com

3 Department of Population Health and Disease Prevention, Program in Public Health, University of California, Irvine, CA 92697, USA

* Author to whom correspondence should be addressed; E-Mail: Oladele.Ogunseitan@uci.edu; Tel.: +1-949-824-0611; Fax: +1-949-824-5209.

Academic Editors: Paul B. Tchounwou and William A. Toscano

Received: 11 April 2015 / Accepted: 10 June 2015 / Published: 15 June 2015

\begin{abstract}
Attention Deficit/Hyperactivity Disorder (ADHD) affects 5\%-8\% of children in the U.S. ( $10 \%$ of males and $4 \%$ of females). The contributions of multiple metal exposures to the childhood behavioral deficits are unclear, although particular metals have been implicated through their neurotoxicity. The objective of this study was to test the hypothesis that the body burden of $\mathrm{Mn}$ is positively correlated with ADHD symptoms. We also investigated the putative roles of $\mathrm{Ca}, \mathrm{Fe}, \mathrm{Pb}$, and $\mathrm{Hg}$. We collected shed molars from 266 children (138 boys and 128 girls) who lost a tooth between 11 and 13 years of age. The molars were analyzed for metals using ICP-OES. The third grade teacher of each child completed the Teacher's Disruptive Behavior Disorders Rating Scale (DBD) to produce a score for "Total Disruptive Behavior" and subscale scores for "Attention Deficit Hyperactivity Disorder", Hyperactivity/Impulsivity, Inattention, and Oppositional/Defiant. The mean Mn, Fe, $\mathrm{Pb}$ and $\mathrm{Ca}$ concentrations found in teeth was $3.1 \pm 2.9 \mu \mathrm{g} / \mathrm{g}, 11.4 \pm 12.1 \mu \mathrm{g} / \mathrm{g}, 0.5 \pm 0.7 \mu \mathrm{g} / \mathrm{g}$, and $3.0 \times 10^{5} \pm 0.8 \times 10^{5} \mu \mathrm{g} / \mathrm{g}$, respectively. $\mathrm{Hg}$ was not detected. No significant association was found between $\mathrm{Mn}$ and behavioral deficits. Ca was significantly negatively associated, and $\mathrm{Pb}$ showed a significant positive association with Hyperactivity/Impulsivity, Inattention, and Oppositional/Defiant Disorders. These findings call into question the putative independent
\end{abstract}


association of manganese exposure and behavioral deficits in children, when the balance of other metallic burden, particularly $\mathrm{Ca}$ and $\mathrm{Pb}$ burdens play significant roles.

Keywords: ADHD; Behavior; Children; Pollution; Teeth; Metals

\section{Introduction}

Attention-Deficit/Hyperactivity Disorder (ADHD) affects 5\%-8\% of children in the United States ( $10 \%$ of males and $4 \%$ of females) (CDC 2002). A definitive cause of ADHD has yet to be discovered, but some of the most promising research on the etiology of ADHD involves investigating the associations between the disorder and exposure to environmental risk factors. One of the potential risk factors is exposure to environmental manganese [1,2].

Manganese $(\mathrm{Mn})$ is a ubiquitous and naturally occurring element found in certain rocks, making up about $0.1 \%$ of the earth's crust [3]. Pure Mn does not occur naturally, but is a component of more than 100 minerals formed when Mn combines with other substances such as oxygen, sulfur, and chlorine. Mn compounds can change naturally or artificially from one compound to another, but the metal is generally stable in the environment [4-6]. Exposure to Mn can occur through inhalation or ingestion, but for most people, exposure to $\mathrm{Mn}$ is usually through diet because $\mathrm{Mn}$ is present in many foods, including tea, grains and cereals, and in drinking water [7]. Human physiology requires a certain amount of $\mathrm{Mn}$, but the internal homeostasis is strictly regulated [8,9]. It is estimated that the average daily diet of an adult provides a range of $1-10 \mathrm{mg}$ of $\mathrm{Mn}[10,11]$. The National Research Council recommends a safe and adequate daily intake level of $5 \mathrm{mg} /$ day for adults [12]. For children, the Food and Nutritional Board of the National Research Council considers daily intake levels of 0.3 to $1 \mathrm{mg} /$ day for children under one years of age, 1 to $2 \mathrm{mg} /$ day for children under 10, and 2 to $5 \mathrm{mg} /$ day for children 10 and older to be safe and adequate [4].

In animals, exposure to excess $\mathrm{Mn}$ has been associated with neurochemical deficits [13-15], neuroanatomical deficits [16,17], neonatal deficits, and executive function deficits [15]. The first reported cases of Mn toxicity in humans occurred among Scottish workers exposed to dusts of grinding Mn ores who developed "a bizarre disorder with both neurological and behavioral components" [18]. These behavioral conditions resulting from chronic exposure to Mn became diagnosed as "manganism" or Mn poisoning. In 1977, the first study was published linking sub-clinical Mn toxicity to children's behavior deficits [19]. A study by Hafeman et al. [20] found that infants exposed to water with manganese levels greater than the 2003 World Health Organization standard of $0.4 \mathrm{mg} / \mathrm{L}$ had higher mortality risk during their first year of life compared to unexposed infants.

The underlying mechanism(s) through which excess $\mathrm{Mn}$ is linked to behavioral disorders is not fully understood. Some scientists speculate that the abnormal behaviors are due to the toxic effects of manganese on the dopaminergic system [21]. The fact that Mn accumulates in dopaminergic areas has prompted studies to determine whether Mn neurotoxicity affects dopaminergic neurotransmission [22]. In vitro studies show that Mn toxicity can decrease intracellular dopamine levels by autoxidation [13]. The resulting Parkinson-like condition demonstrates that "Mn is specifically toxic to the brain's 
dopamine systems" [22]. A similar study implicated $\mathrm{Mn}$ in causing the decay of dopamine by catalyzing the oxidation of the dopamine ligand [23]. This is similar to the neurotoxic effect of impaired dopaminergic functioning seen in children with ADHD. New-born animals that receive excess doses of Mn during their first few weeks of life show abnormalities in the dopaminergic nigrostratial system. These animal studies have shown that $\mathrm{Mn}$ exposure can lead to neurotoxic damage or dopamine deficits in the dopaminergic systems within the brain [24,25].

There are several methods for measuring Mn concentrations in humans. Mn in the blood is the most widely accepted method of measurement. The main limitation of using blood is that it only provides a reliable indication of recent exposure to $\mathrm{Mn}$. The estimated half-life of $\mathrm{Mn}$ in the body is 37 days [26]. For records of exposure over longer periods of time, hair has been utilized, because hair protein absorbs excreted Mn from diet [2,27]. But similar to blood, the exposure assessment from hair is generally short, with measurements accounting for an exposure history of only a few months on average [27]. Neutron activation analysis of the liver has also been conducted to determine recent $\mathrm{Mn}$ exposure [28]. In contrast, analysis of the deciduous tooth enamel allows measurements of $\mathrm{Mn}$ exposure, going as far back as the 20th week gestation and as recent as 63rd gestational week [29] because calcified tissues incorporate heavy metals to which they are exposed during development [30]. This is important as the time frame coincides with neuronal development occurring within the brain [31]. Complete tooth formation occurs during the early postnatal stages of a child's development, but tertiary or reactive/reparative dentin is continually produced when needed, such as replacing existing dentin destroyed by caries. In addition, subsurface enamel loss from such events as caries can be remineralized from $\mathrm{Ca}$ and phosphate ion in saliva as long as there is no breakdown of the surface layer. During the reparative and remineralization process, $\mathrm{Mn}$ and other metals are deposited in teeth just as it would during tooth development. During tooth formation and mineralization, Ca absorbed can be partially substituted by heavy metals [32] and the relative stable nature of dental tissue allows a large extent of these metals deposited in the teeth during mineralization to be retained [33].

Some published studies have shown significant correlations between elevated Mn hair levels and increased expression of behavioral deficits in children [2,34,35]. There have also been studies published using human teeth as a potential biomarker of environmental exposure to heavy metals [1,36,37], but few have then concurrently compared the measured Mn exposure to behavioral measurements of the subjects. Findings from a study using 27 teeth from 27 children as a biomarker for Mn exposure suggested that prenatal accretion of $\mathrm{Mn}$ in tooth enamel is significantly associated with more frequent hyperactive, impulsive, inattentive, aggressive, defiant, destructive and disobedient behavior [29]. This study expands upon these previous experiments in investigating the role of $\mathrm{Mn}$ in the development of ADHD and other behavioral deficits by specifically testing the hypothesis that high body burden of manganese is positively correlated with ratings of ADHD.

In addition to $\mathrm{Mn}$ concentrations, the levels of iron $(\mathrm{Fe})$, calcium $(\mathrm{Ca})$ and lead $(\mathrm{Pb})$ and mercury $(\mathrm{Hg})$ within the teeth were investigated in order to assess their putative roles independently or in interactive ways. $\mathrm{Fe}$ and $\mathrm{Ca}$ are of particular interest because studies indicate that $\mathrm{Mn}$ absorption in the human body can be affected by deficiencies in $\mathrm{Fe}$ [38,39] and $\mathrm{Ca}[40]$. Fe deficiency is considered the most widespread nutritional deficiency among children [41,42] and Mn is initially absorbed via the same biological pathway as Fe (i.e., the intestine does not differentiate between $\mathrm{Mn}$ and Fe) [43-45]. 
Evidence from animal studies indicates that $\mathrm{Mn}$ displays an inverse relation with dietary $\mathrm{Fe}$ concentrations [4]. Therefore, dietary Fe deficiency leads to increased $\mathrm{Mn}$ absorption and toxicity whereas high levels of Fe lead to decreased Mn absorption and toxicity [46-49]. Conversely, high levels of dietary Mn lead to lower Fe absorption [43,49]. Fe deficiency has also been correlated with child behavioral abnormalities [50]. Short-term causes of the relation between Fe and $\mathrm{Mn}$ are believed to be the result of kinetic competition between the two metals for available binding sites on intestinal transport enzymes [51] while long-term causes are believed to be the result of adaptive changes in intestinal transport capacity [18]. Competition between Fe and Mn has been reported to extend to the blood-brain barrier, indicating that high levels of either metal will affect the brain distribution of the other metal [52].

Calcium deficiency has been suggested in animal studies to cause Mn neurotoxicity by increasing dietary Mn absorption and Mn levels in the brain e.g. [40]. A similar study found that rats fed a low Ca diet showed significantly higher Mn levels in the frontal cortex and suggested that these types of unbalanced mineral diets and metal-metal interactions may lead to CNS degeneration [53]. Pb was also included in the study because $\mathrm{Pb}$ toxicity in biological systems has been extensively documented [54] and low-level exposure has also been associated with cognitive and behavioral deficits in children [55]. Determining the concentration levels of these additional elements linked to behavioral disorders will aid in establishing whether these elements are potential causes in the behavioral deficits observed in this study population.

\section{Materials and Methods}

Shed molars were collected from 266 children in the NICHD Study of Early Child Care and Youth Development (SECCYD) who lost a tooth between 11 and 13 years of age. The parents voluntarily submitted the teeth, which were subsequently stored in snap-lock plastic containers. The families that donated teeth were not significantly different from the other 714 families in the SECCYD sample in terms of family income, ethnicity, or child behavioral outcomes. However, the parents who donated their child's tooth had significantly higher education levels (14.7 years vs. 14.1 years, $p<0.05$ ).

\subsection{Behavioral Measures}

Third grade teachers completed the Disruptive Behavior Disorders (DBD) Rating Scale. Twenty-six behavior items were scored on a 4-point scale composed of $0=$ not at all, $1=$ just a little, $2=$ pretty much, 3 = very much. The DBD scale was derived from the Diagnostic and Statistical Manual of Mental Disorders (DSM-IV) and produces a Total Disruptive Behavior Score as well as subscale scores for ADHD, Inattention, Hyperactivity/Impulsivity, and Oppositional Defiance [56,57]. The Disruptive Behavior Disorder Total Score is computed as the sum of the items 1 to 26 . The possible scores range from 0 to 78 , with higher scores indicating more hyperactive-impulsive, inattentive, and oppositional defiant behaviors. The Oppositional Defiant Score is computed as the sum of eight items producing a score ranging from 0 to 24 . Hyperactive-Impulsive and Inattentive Scores are computed as the sum of nine separate items for each behavior type. The possible scores for both forms of behavior are 0 to 27 . The ADHD score is computed as the sum of the 18 hyperactive and inattentive items. The possible scores range from 0 to 54, with higher scores indicating more attention 
deficit-hyperactive behaviors. The reliabilities of these scales (Cronbach's alphas) are 0.96 for the 26-item Total Disruptive Behavior Disorder Score, 0.95 for the 18-item Attention Deficit/Hyperactivity Disorder Score, 0.93 for the 9-item Hyperactive-Impulsive Score, 0.95 for the Inattentive Score, and 0.93 for Oppositional Defiant Score. Pelham et al. [68] reported internal consistency of 0.96, 0.95, and 0.95 for Oppositional Defiance, Inattention, and Hyperactivity-Impulsivity respectively.

\subsection{Preparation and Analysis of Teeth}

Two hundred and sixty six molar teeth were longitudinally sectioned with a diamond blade on an Isomet low speed saw (Buehler, Lake Bluff, IL, USA). One half of the molar tooth was utilized for metal concentration analysis. Tooth samples were washed thoroughly with distilled deionized water. The samples were first air-dried and then later dried at $85^{\circ} \mathrm{C}$ to a constant mass before being pulverized using a glass pestle and mortar. After pulverization, each sample was further dried at $85^{\circ} \mathrm{C}$ for $240 \mathrm{~min}$ and weighed prior to digestion [37].

Manganese $(\mathrm{Mn})$, iron $(\mathrm{Fe})$, calcium $(\mathrm{Ca})$, mercury $(\mathrm{Hg})$ and lead $(\mathrm{Pb})$ concentrations were determined through Inductively Coupled Plasma-Optical Emission Spectroscopy (ICP-OES). EPA 6010 Method was used to determine $\mathrm{Mn}, \mathrm{Fe}, \mathrm{Ca}$, and Pb concentrations; EPA 7471 Method was used for $\mathrm{Hg}$. Sensitivity limits of the ICP-OES are $0.01 \mathrm{mg} / \mathrm{L}$ for $\mathrm{Mn}, \mathrm{Fe}, \mathrm{Ca}, \mathrm{Pb}$ and $0.0002 \mathrm{mg} / \mathrm{L}$ for $\mathrm{Hg}$. The weights for the sample teeth ranged from 120 to $580 \mathrm{mg}$ per tooth sample with an average of $280 \mathrm{mg}$. A sample weighing $250 \mathrm{mg}$ of dried powdered tooth was digested with $1.5 \mathrm{~mL}$ of concentrated nitric acid in a Teflon vessel at $120{ }^{\circ} \mathrm{C}$ for $180 \mathrm{~min}$ before being diluted with distilled water to $5 \mathrm{~mL}$. The volume of concentrated nitric acid and distilled water were adjusted accordingly for samples weighing less or more than $250 \mathrm{mg}$. Instrument-calibrated element standards were used as controls for experimental sample measurements. The measured metal concentrations were not adjusted for teeth dry weight or for loss of organic matter during the digestion procedure.

\subsection{Statistical Analyses Linear Associations}

SPSS version 10.0 (SPSS, Chicago, IL, USA) was used for the statistical analyses. Three sets of linear regression models were fit to determine whether a significant association exists between the concentration of each metal and the behavioral deficit assessments ( $p=0.05$ level of significance). The first set of analyses evaluated the bivariate associations. The second set of analyses controlled for the child's race, gender, paternal education, maternal education, marital status of parents, and family social economic status. The third set of regression models determined whether there was an association between each metal and the behavioral measurements controlling for the other four elements.

\subsection{Dichotomous Comparisons}

Unpaired $\mathrm{t}$ tests were performed comparing the 50 subjects with the highest DBD, ADHD, Inattention, Hyperactivity/Impulsivity, and Oppositional Defiant scores to 50 subjects with DBD, ADHD, Inattention, Hyperactivity/Impulsivity, and Oppositional Defiant scores of zero. Unpaired $\mathrm{t}$ tests were also performed comparing subjects who meet the criteria for DSM-IV diagnoses of DBD, ADHD, Inattention, Hyperactivity/Impulsivity, and Oppositional Defiance to those subjects showing 
no symptoms of these disorders. Children who met the criteria for DSM-IV diagnoses scored two standard deviations above the normative mean obtained by the 980 subjects in the national sample participating in the NICHD Study of Early Child Care and Youth Development [57].

\section{Results}

The ratio of males to females in the study was 138 to 128 respectively. Of the participants, 234 identified as White, 19 as African American, 4 as Asian, and 8 as other. Eighty-four percent or 224 of the children came from families in which the parents were married and living together. The income of the families ranged from $\$ 2000$ to $\$ 230,000$ with an average of $\$ 56,988$ and a median of $\$ 47,500$. The number of teeth collected from each study site was as follows: Little Rock, $\mathrm{AR}=26$, Irvine, $\mathrm{CA}=19$, Lawrence, $\mathrm{KS}=11$, Boston, $\mathrm{MA}=35$, Pittsburgh, $\mathrm{PA}=24$, Philadelphia, $\mathrm{PA}=26$, Charlottesville, $\mathrm{VA}=21$, Seattle, $\mathrm{WA}=40$, Morganton, $\mathrm{NC}=23$ and Madison, $\mathrm{WI}=41$. These characteristics are summarized in Table 1.

Table 1. Descriptive characteristics of the 266 study participants.

\begin{tabular}{|c|c|c|c|}
\hline Characteristic & \multicolumn{3}{|l|}{ Values } \\
\hline & \multicolumn{3}{|c|}{ Charlottesville, $\mathrm{VA}=21$} \\
\hline & \multicolumn{3}{|c|}{ Irvine, $\mathrm{Ca}=19$} \\
\hline & \multicolumn{3}{|c|}{ Lawrence, $\mathrm{KS}=11$} \\
\hline & \multicolumn{3}{|c|}{ Little Rock, AR $=26$} \\
\hline & \multicolumn{3}{|c|}{ Madison, $\mathrm{WI}=41$} \\
\hline Site Location and Number of Subjects & \multicolumn{3}{|c|}{ Morganton, $\mathrm{NC}=23$} \\
\hline & \multicolumn{3}{|c|}{ Philadelphia, $\mathrm{PA}=26$} \\
\hline & \multicolumn{3}{|c|}{ Pittsburgh, PA = 24} \\
\hline & \multicolumn{3}{|c|}{ Seattle, $\mathrm{WA}=40$} \\
\hline & \multicolumn{3}{|c|}{ Boston, $\mathrm{MA}=35$} \\
\hline \multirow{4}{*}{ Ethnicity } & \multicolumn{3}{|c|}{ African American $=19$} \\
\hline & \multicolumn{3}{|c|}{ Asian $=4$} \\
\hline & \multicolumn{3}{|l|}{ Other $=8$} \\
\hline & \multicolumn{3}{|l|}{ White $=234$} \\
\hline \multirow{2}{*}{ Marital Status } & \multicolumn{3}{|l|}{ Married $=224$} \\
\hline & \multicolumn{3}{|l|}{ Single $=42$} \\
\hline \multirow{3}{*}{ Gender } & \multicolumn{3}{|l|}{ Male $=138$} \\
\hline & \multicolumn{3}{|l|}{ Female $=128$} \\
\hline & Range & Average & Median \\
\hline Mother's Education (Years) & $7-21$ & 14.9 & 14 \\
\hline Father's Education (Years) & $9-21$ & 15.2 & 14 \\
\hline Income (US\$) & $2000-230,000$ & 56,000 & 47,000 \\
\hline
\end{tabular}

Results for behavioral measures and metal analysis are shown in Table 2 . The children in this study had average behavioral scores of $11.60 \pm 13.77$ for DBD, $9.44 \pm 11.01$ for ADHD, $4.34 \pm 5.82$ for Hyperactivity/Impulsivity, $5.11 \pm 6.22$ for Inattention, and $2.16 \pm 3.75$ for Oppositional Defiance. The DBD total score for the children must be larger than their respective subscale scores, including $\mathrm{ADHD}$. The mean $\mathrm{Mn}, \mathrm{Fe}, \mathrm{Pb}$ and $\mathrm{Ca}$ concentrations found in teeth was $3.1 \pm 2.9 \mu \mathrm{g} / \mathrm{g}$, 
$11.4 \pm 12.1 \mu \mathrm{g} / \mathrm{g}, 0.5 \pm 0.7 \mu \mathrm{g} / \mathrm{g}$, and $3.0 \times 10^{5} \pm 0.8 \times 10^{5} \mu \mathrm{g} / \mathrm{g}$, respectively. Mercury was not detected in any of the teeth.

Table 2. Average behavioral measure scores and metal concentrations.

\begin{tabular}{|c|c|c|c|c|c|c|c|c|c|c|}
\hline \multirow{3}{*}{$\begin{array}{l}\text { Statistical } \\
\text { Parameter }\end{array}$} & \multicolumn{5}{|c|}{ Behavioral Measures } & \multicolumn{5}{|c|}{ Metal Concentrations $(\mu \mathrm{g} / \mathrm{g})$} \\
\hline & \multicolumn{4}{|c|}{ Hyperactive } & \multirow{2}{*}{$\begin{array}{c}\text { Oppositional } \\
\text { Defiant } \\
\end{array}$} & \multirow{2}{*}{$\mathbf{C a}$} & \multirow{2}{*}{$\mathbf{F e}$} & \multirow{2}{*}{$\mathbf{P b}$} & \multirow{2}{*}{ Mn } & \multirow{2}{*}{ Hg } \\
\hline & DBD & ADHD & Impulsive & Inattention & & & & & & \\
\hline $\mathrm{N}$ & 266 & 266 & 266 & 266 & 265 & 265 & 261 & 266 & 262 & 266 \\
\hline Mean & 11.60 & 9.44 & 4.34 & 5.11 & 2.16 & $3.18 \times 10^{5}$ & 11.34 & 0.46 & 3.06 & - \\
\hline SD & 13.77 & 11.01 & 5.82 & 6.22 & 3.75 & $0.84 \times 10^{5}$ & 12.06 & 0.73 & 2.85 & - \\
\hline
\end{tabular}

$\mathrm{N}$-Sample size; SD—Standard Deviation.

\subsection{Bivariate Associations}

Linear regression models indicated no significant association between the behavioral deficit scores and the concentrations of metals in teeth, with the exception of $\mathrm{Ca}$ (Table 3). Low levels of Ca were related to higher behavioral deficit scores: DBD (Beta $=-0.25, p<0.01)$, ADHD (Beta $=-0.25$, $p<0.01$ ), Hyperactivity/Impulsivity (Beta $=-0.25, p<0.01$ ), Inattention (Beta $=-0.21, p<0.01$ ), Oppositional Defiance (Beta $=-0.20, p<0.01$ ). Effect sizes using Cohen's guidelines for a small $\left(\mathrm{r}^{2}=0.01\right)$, medium $\left(\mathrm{r}^{2}=0.06\right)$, large $\left(\mathrm{r}^{2}=0.14\right)$ were of medium size for DBD, ADHD, and Hyperactivity/Impulsivity and a small to medium size effect for Inattention and Oppositional Defiance. Results for Fe approached significance for three of the behavioral scores, showing an inverse association with $\mathrm{DBD}(\mathrm{B}=-0.10, p=0.093)$, ADHD $(\mathrm{B}=-0.10, p=0.091)$, and Hyperactivity/Impulsivity $(\mathrm{B}=-0.11, p=0.07)$.

Table 3. Bivariate associations between the behavioral scores and metal concentrations.

\begin{tabular}{|c|c|c|c|c|c|c|}
\hline \multirow{2}{*}{ Metal } & \multirow{2}{*}{ Statistical Parameters } & \multicolumn{4}{|c|}{ Hyperactive } & \multirow{2}{*}{$\begin{array}{c}\text { Oppositional } \\
\text { Defiance } \\
\end{array}$} \\
\hline & & DBD & ADHD & Impulsive & Inattention & \\
\hline \multirow{3}{*}{$\mathrm{Mn}$} & Beta & 0.06 & -0.06 & -0.08 & -0.02 & -0.07 \\
\hline & $\mathrm{R}^{2}$ & 0.004 & 0.003 & 0.007 & 0.001 & 0.004 \\
\hline & $\mathrm{N}$ & 262 & 262 & 262 & 262 & 261 \\
\hline \multirow{3}{*}{$\mathrm{Ca}$} & Beta & $-0.25 * * *$ & $-0.25 * * *$ & $-0.25 * * *$ & $-0.21 * * *$ & $-0.20 * *$ \\
\hline & $\mathrm{R}^{2}$ & 0.004 & 0.003 & 0.007 & 0.001 & 0.004 \\
\hline & $\mathrm{N}$ & 265 & 265 & 265 & 265 & 264 \\
\hline \multirow{3}{*}{$\mathrm{Fe}$} & Beta & -0.10 & -0.10 & -0.11 & -0.08 & -0.08 \\
\hline & $\mathrm{R}^{2}$ & 0.011 & 0.011 & 0.013 & 0.007 & 0.006 \\
\hline & 261 & 261 & 261 & 261 & 260 & 261 \\
\hline \multirow{3}{*}{$\mathrm{Pb}$} & Beta & -0.05 & -0.03 & -0.06 & 0.00 & -0.09 \\
\hline & $\mathrm{R}^{2}$ & 0.002 & 0.001 & 0.003 & 0.000 & 0.008 \\
\hline & $\mathrm{N}$ & 266 & 266 & 266 & 266 & 265 \\
\hline
\end{tabular}




\subsection{Adjusted Effects}

Linear regression models controlling for race, sex, paternal education, maternal education, marital status of parents, and family social economic status produced similar results. Ca was the only metal showing a significant association with the behavioral scores, with the exception of Inattention (see Table 4). The beta coefficients for Ca were slightly smaller in magnitude: DBD (Beta $=-0.15$, $p=0.014)$, ADHD (Beta $=-0.15, p=0.017)$, Hyperactivity/Impulsivity (Beta $=-0.17, p<0.01)$, Oppositional Defiance (Beta $=-0.12, p=0.05$ ), and Inattention (Beta $=-0.10, p=0.10)$. Results for Fe no longer approached significance when controlling for the covariates. Similarly, linear regression models showed $\mathrm{Ca}$ being the only metal to show a significant association with the behavioral scores when controlling for the other three metals (see Table 5): DBD (Beta $=-0.238, p<0.001$ ), ADHD (Beta $=-0.234, p<0.001)$, Hyperactivity/Impulsivity (Beta $=-0.236, p<0.001$ ), Oppositional Defiance $($ Beta $=-0.195, p=0.003)$, and Inattention $($ Beta $=-0.189, p=0.004)$.

Table 4. Association between behavior scores and metal concentrations controlling for covariates ${ }^{\text {a. }}$.

\begin{tabular}{|c|c|c|c|c|c|c|}
\hline \multirow{2}{*}{ Metal } & \multirow{2}{*}{ Statistical Parameters } & \multicolumn{4}{|c|}{ Hyperactive } & \multirow{2}{*}{$\begin{array}{c}\text { Oppositional } \\
\text { Defiance }\end{array}$} \\
\hline & & DBD & ADHD & Impulsive & Inattention & \\
\hline \multirow{2}{*}{$\mathrm{Mn}$} & Beta & -0.011 & -0.007 & -0.039 & 0.025 & -0.020 \\
\hline & $\mathrm{N}$ & 231 & 231 & 231 & 231 & 231 \\
\hline \multirow{2}{*}{$\mathrm{Ca}$} & Beta & $-0.152 *$ & $-0.15 *$ & $-0.171 * *$ & -0.105 & $-0.119 *$ \\
\hline & $\mathrm{N}$ & 233 & 233 & 233 & 233 & 233 \\
\hline \multirow{2}{*}{$\mathrm{Fe}$} & Beta & -0.072 & -0.078 & -0.092 & -0.051 & -0.04 \\
\hline & $\mathrm{N}$ & 230 & 230 & 230 & 230 & 230 \\
\hline \multirow{2}{*}{$\mathrm{Pb}$} & Beta & -0.027 & -0.006 & -0.023 & 0.011 & -0.080 \\
\hline & $\mathrm{N}$ & 234 & 234 & 234 & 234 & 234 \\
\hline
\end{tabular}

${ }^{a}$ controlling for race, sex, paternal education, maternal education, marital status of parents, and family social; economic status; * $p<0.05 ; * * p<0.01$.

Table 5. Association between behavior scores and individual metal concentrations controlling for the other four metals.

\begin{tabular}{ccccccc}
\hline \multirow{2}{*}{ Metal } & Statistical & \multicolumn{3}{c}{ Hyperactive } & \multicolumn{2}{c}{ Oppositional } \\
\cline { 2 - 6 } & Parameters & DBD & ADHD & Impulsive & Inattention & Defiance \\
\hline \multirow{2}{*}{$\mathrm{Mn}$} & Beta & 0.051 & 0.056 & 0.035 & 0.067 & 0.026 \\
& $\mathrm{~N}$ & 260 & 260 & 260 & 260 & 260 \\
$\mathrm{Ca}$ & $\mathrm{Beta}$ & $-0.238 * * *$ & $-0.234 * * *$ & $-0.236 * * *$ & $-0.195 * *$ & $-0.189 * *$ \\
& $\mathrm{~N}$ & 260 & 260 & 260 & 260 & 260 \\
$\mathrm{Fe}$ & $\mathrm{Beta}$ & -0.078 & -0.081 & -0.080 & -0.070 & -0.049 \\
& $\mathrm{~N}$ & 260 & 260 & 260 & 260 & 260 \\
$\mathrm{~Pb}$ & $\mathrm{Beta}$ & -0.009 & 0.008 & -0.022 & 0.035 & -0.055 \\
& $\mathrm{~N}$ & 260 & 260 & 260 & 260 & 260 \\
\hline
\end{tabular}




\subsection{Comparison of Metal Levels for Low and High Behavioral Deficit Groups}

Additional analyses were conducted to compare concentrations of metals for the 50 subjects with the highest and the lowest behavioral scores (Table 6). Results of unpaired t-tests indicated no significant differences in $\mathrm{Mn}$ and $\mathrm{Fe}$. Ca was significantly higher in the group with the lowest when compared to the group with the highest behavior scores for three of the behavior measurements, DBD, ADHD, and Hyperactivity/Impulsivity (see Figure 1A). Pb was significantly higher in the group with the highest scores for Inattention, Hyperactivity/Impulsivity, and Oppositional Defiance (see Figure 1B). Using Cohen's guidelines for a small $\left(r^{2}=0.01\right)$, medium $\left(r^{2}=0.06\right)$, large $\left(r^{2}=0.14\right)$ effect sizes were moderate. Unpaired t-tests conducted to compare subjects who met the criteria for DSM-IV diagnosis of DBD, ADHD, Inattention, Oppositional Defiance, and Hyperactivity/Impulsivity to subjects showing no measured symptoms of the respective disorders did not attain significance.

Table 6. Mean metal concentrations $(\mu \mathrm{g} / \mathrm{g}$ ) for the 50 subjects with the highest behavioral scores and the 50 subjects with the lowest behavioral scores (SD-Standard Deviation).

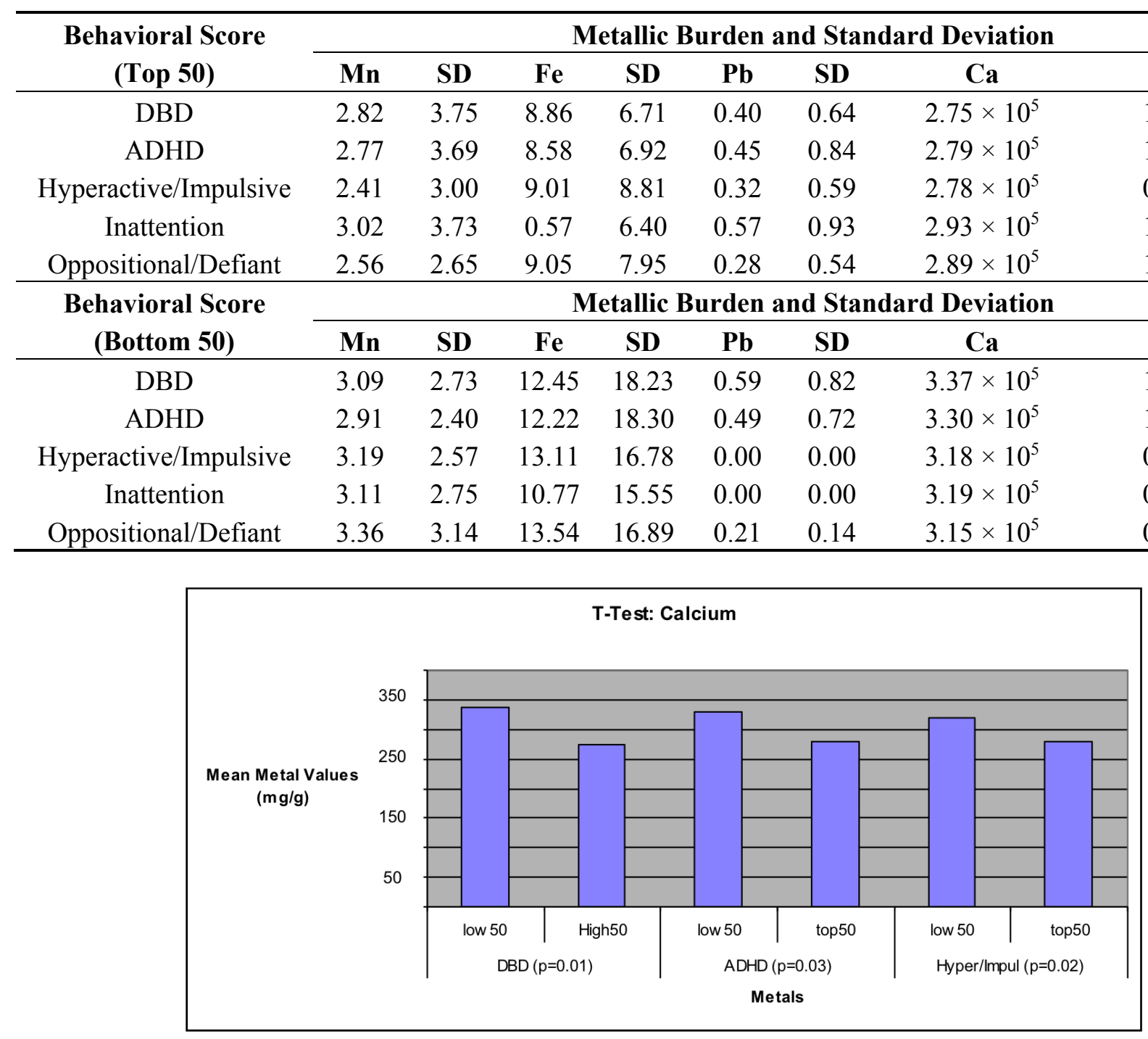

(A)

Figure 1. Cont. 


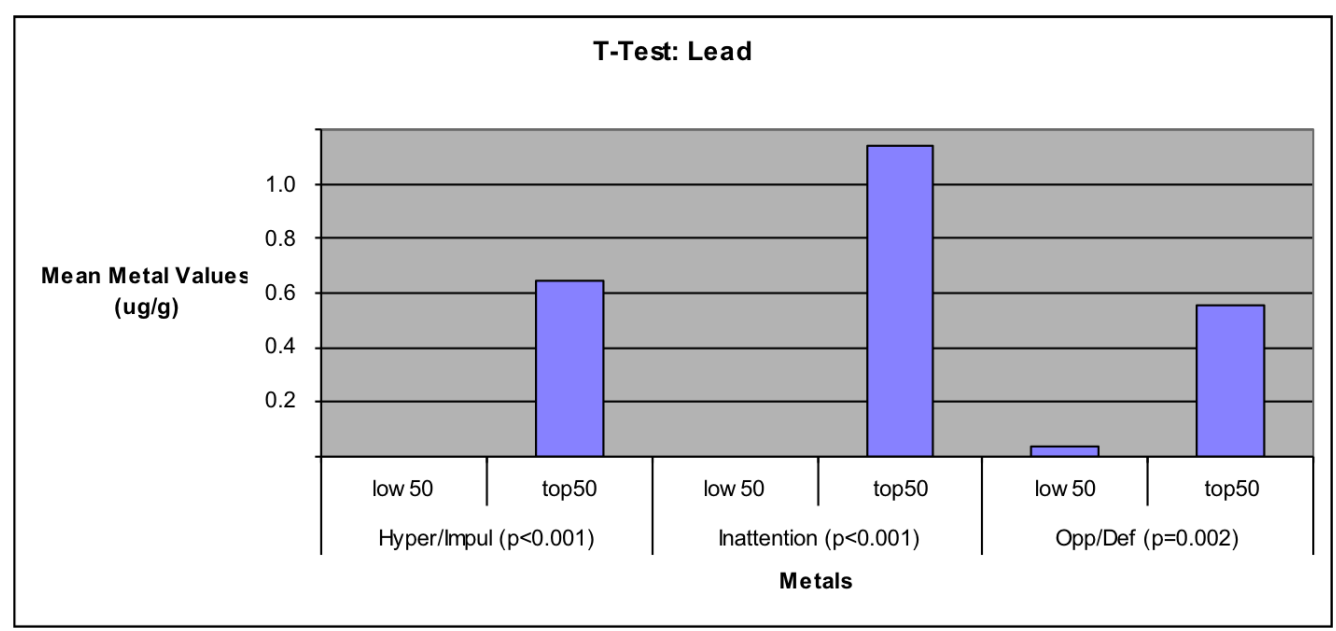

(B)

Figure 1. Significant mean metal concentrations of $\mathrm{Ca}(\mathbf{A})$ and $\mathrm{Pb}(\mathbf{B})$ for the 50 subjects with the highest behavioral scores and the 50 subjects with the lowest behavioral scores.

\section{Discussion}

The results of this study indicate that there is no significant association between Mn levels found in deciduous teeth and measurements of behavioral deficit in children. The results did not achieve statistical significance even after adjustment for race, sex, paternal education, maternal education, marital status of parents, and family social economic status. The elements $\mathrm{Ca}$ and Fe, previously shown to influence $\mathrm{Mn}$ absorption in the human body were added to regression models to help determine if the association between $\mathrm{Mn}$ and the behavior measurements may have been modified by these two environmental risk factors $[38,40,58]$. These findings contradict previous studies that indicate a significant association between elevated $\mathrm{Mn}$ concentrations and behavioral deficits in children $[2,59]$.

There was no significant association found between Fe levels in the teeth and the behavioral measurements. These results also contradict previous studies that suggest low Fe levels contribute to ADHD symptoms [60,61]; instead supporting opposing studies that indicate Fe deficiency does not contribute to ADHD [62]. No statistical analysis was performed to test the relationship between $\mathrm{Hg}$ and the behavioral measurements as $\mathrm{Hg}$ levels in the teeth were below the detection limit of the instrument.

The results showed significant negative associations between $\mathrm{Ca}$ concentration levels and all five behavioral measurements, indicating that higher levels of $\mathrm{Ca}$ was associated with decreased occurrences of behavioral problems measured in the children. These relations remained significant after adjustment for the other metals as well as race, sex, paternal education, maternal education, marital status of parents, and family social economic status. Unpaired t-test tests comparing the 50 subjects with the highest behavioral scores to the 50 with the lowest also showed this same significant negative relation, but only for three of the behavior measures (DBD, ADHD, and Hyperactivity/Impulsivity). Further study is needed to determine why Inattention and Oppositional Defiance were not significant. These associations further support the importance of $\mathrm{Ca}$ in human 
physiology. The importance of $\mathrm{Ca}$ in promoting strong bones has been well documented [63-66], but this and other studies have also demonstrated the potential importance of $\mathrm{Ca}$ in regards to child behavior [67,68]. Studies have indicated that deficiencies in calcium and other biochemicals is associated with higher incidents of childhood behavioral deficits [68] while the activity of calcium channels has been suggested in helping reduce the negative symptoms of schizophrenia [67]. Furthermore, correlation models from this study show Ca levels positively correlated with higher levels of the other three metals (Table 7). This would indicate that children with higher Ca levels are probably more likely to be receiving a proper diet of other essential nutrients. This proper diet can help promote normal development in the children, thus, potentially explaining the lower levels of behavioral deficits observed in the children of this study.

Table 7. Bivariate correlations between $\mathrm{Ca}$ and other metals.

\begin{tabular}{ccccc}
\hline \multirow{2}{*}{ Metal } & Statistical Parameter & \multicolumn{4}{c}{ Metal } \\
\cline { 3 - 5 } & Partial Correlation & $0.190 * *$ & Pb & Mn \\
\hline \multirow{2}{*}{$\mathrm{Ca}$} & Sample Size $(\mathrm{N})$ & 261 & $0.191 * *$ & $0.346 * * *$ \\
& \multicolumn{4}{c}{$* * p<0.01 ; * * * p<0.001}$.
\end{tabular}

The additional findings in this study that elevated $\mathrm{Pb}$ levels is significantly associated with increased incidents of Hyperactivity/Impulsivity, Inattention, and Oppositional Defiance in children also support the well documented toxic effects of $\mathrm{Pb}$ on the human body [54] and its association with cognitive and behavioral deficits in children [55].

\subsection{Limitations}

There are several important limitations to this project. First, the participants were not randomly selected but were instead self-selected and it is possible that the parents who felt their children had no observable behavioral problem were more willing to send in the child's tooth for analysis. In addition, the parents who donated their child's tooth had significantly higher education levels (14.7 years vs. 14.1 years, $p<0.05$ ) [29]. The more educated parents may have better understood the importance of submitting the teeth for analysis and were more dedicated to sending in samples. Second, there are presently no set low, medium or high concentration levels for these environmental risk factors within teeth. All concentrations measured can only be used relative to other samples in the study when analyzing teeth. Third, the tooth does not present an absolute log of the environmental exposure during the children's lives. The tooth is biased toward the 20th week gestation to the 63rd gestational weeks of a child's development [29]. Any time after this period is dependent on whether there was any tertiary repair of dentin or re-mineralization of the subsurface enamel. A child may display behavioral problems caused by acute or chronic exposure to environment toxins after the 63rd gestational week that may not be detected in the tooth. Fourth, although we took extensive methodological care to avoid cross-contamination across samples, and to avoid interference from tissue not associated with teeth, we are aware that other potentially aggressive methods such as hydrogen peroxide soaking are sometime used. We also note the large standard deviations in the metal measurements, and the fact that we did not correct for metal concentrations with respect to changes associated with tooth preparation 
processes, including drying, grinding, and acid digestion, and we relied on calibrated instrument standards as controls. We prioritized methodological standardization based on similar published research from our laboratory, and the results of our chemical analysis procedures are consistent with other published studies using teeth as a biomarker of exposure $[1,37]$.

\subsection{Implications}

Despite the limitations, the results of this study are valuable additions to the growing research in investigating the relationships between environmental toxicants and behavioral deficits, and the use of biomarkers to measure these associations. This study represents one of the largest sample sizes to date for this type of experiment, giving it greater statistical power. Although no significant associations were found between manganese and the behavioral deficit scores, the significant findings on $\mathrm{Pb}$ and especially $\mathrm{Ca}$ are further evidence of the important roles these two elements play in child development. The results of this and other studies have not only acknowledged the potential harms of $\mathrm{Pb}$ toxicity [54] but has also advanced the role of calcium in human physiology beyond bone growth and development and into the realm of cognitive function $[67,68]$.

The tooth does not represent a perfect biomarker, but its proven effectiveness at accumulating and storing heavy metals [37] provides an effective method of measuring environmental exposure during the early stages of a child's development. Recent studies support the view that Manganese levels in tooth dentine show promise as a biomarker of perinatal exposure $[69,70]$ but cannot make such a claim based on the present study because we did not conduct a comparative assessment of biomarkers. Biomarkers such as hair and blood are reputably effective at measuring recent exposure. Future research, if possible, should consider incorporating the use of both the subjects tooth and hair/blood as biomarkers. The combined usage of teeth to measure early exposure and hair/blood to measure recent exposure provides the most accurate and comprehensive log of a subject's exposure history to environmental contaminates.

\section{Conclusions}

Unlike lead and mercury that are unequivocally toxic at all levels of exposure, manganese in diet is essential for normal human development and maintenance of health. Healthy individuals with normal physiological functions can regulate excessive levels of required metals such as calcium, iron, and manganese. However, excessive levels of manganese and routes of exposure such as inhalation are known to elicit adverse health outcomes. Previous research suggested that manganese accumulation in teeth is linked to measurable behavioral deficits in children. Through this research, based on a larger sample size than previously possible, we found no significant relationship between dental manganese and behavioral deficits, and we reconfirmed the adverse impacts of lead exposure. The detected protective effect of calcium levels warrants further investigation, and the results on manganese has implications for attempts to regulate the acceptable levels of manganese in water supply and diet components. 


\section{Acknowledgments}

This research was supported in part by grants from the NIH (5 U01 Hd33343-05), NICHD Study of Early Child Care and Youth Development (HD-25456), the National Science Foundation's Biocomplexity in the Environment-Materials Use: Science, Engineering, and Society (MUSES) Program (DMII 0223894) and by the UC Systemwide Research Education in Green Materials Program (UC 44157). The authors declare they have no competing financial interests. We thank Frank Crinella for comments on earlier versions of this manuscript. This work is dedicated to the memories of Professors Jonathon Ericson and Alison Clark-Stewart.

\section{Author Contributions}

Tony Chan and Oladele Ogunseitan contributed to the study design, data analysis and manuscript writing. Tony Chan further contributed to sample collection, survey data collation, and Carolina Guttierez contributed to sample collection, processing, and data analysis.

\section{Conflicts of interest}

The authors declare no conflict of interest.

\section{References}

1. Ericson, J.E.; Rinderknecht, A.; Gonzalez, E.J.; Crinella, F.M.; Kleinman, M.T. Measurements of manganese with respect to calcium in histological enamel cross sections: Toward a new manganese biomarker. Environ. Res. Sec. A 2001, 86, 46-50.

2. Bouchard, M.; Laforest, F.; Vandelac, L.; Bellinger, D.; Mergler, D. Hair manganese and hyperacitive behaviors: Pilot study of school-age children exposed through tap water. Environ. Health Perspect. 2007, 1151, 122-127.

3. Graedel, T.E. Inorganic elements, hydrides, oxides, and carbonates. In Chemical Compounds in the Atmosphere; Academic Press: New York, NY, USA, 1978; pp. 35-41, 44-49.

4. Agency for Toxic Substances and Disease Registry ATSDR. Toxicological Profile for Manganese; Atlanta, G.A., Ed.; U.S. Department of Health and Human Services, Public Health Service: Washington, DC, USA, 2000.

5. Bhuie, A.K.; Ogunseitan, O.A.; Roy, D.N. Manganese content of Tradescancia. species exposed to automotive combustion of methylcyclopentadienyl manganese tricarbonyl in urban and rural landscapes. J. Air Waste Manag. Assoc. 2004, 54, 181-190.

6. Bhuie, A.K.; Ogunseitan, O.A.; Sain, M.; Roy, D.N. Modeling the environmental fate of manganese from methylcyclopentadienyl manganese tricarbonyl in urban landscapes. Sci. Total Environ. 2005, 339, 167-178.

7. U.S. EPA. Drinking Water Criteria Document for Manganese; EPA/ECAO-CIN-D008; US Environmental Protection Agency, Office of Health and Environmental Assessment: Cincinnati, OH, USA, 1993. 
8. Folsom, T.R.; Young, D.R.; Johnson, J.N.; Pillai, K.C. Manganese-54 and zince-65 in coastal organisms of California. Nature 1963, 200, 327-329.

9. Thompson, S.E.; Burton, C.A.; Quinn, D.J.; Ng, Y.C. Concentration Factors of Chemical Elements in Edible Aquatic Organisms; Lawrence Livermore Laboratory, Bio-Medical Division, University of California: Livermore, CA, USA, 1972.

10. Freeland-Graves, J. Derivation of manganese estimated safe and adequate daily dietary intakes. In Risk Assessment of Essential Elements; Mertz, W., Abernathy, C.O., Olin, S.S., Eds.; International Life Sciences Institute Press: Washington, DC, USA, 1994.

11. Gibson, R.S. Content and bioavailability of trace elements in vegetarian diets. Am. J. Clin. Nutr. 1994, 59, 1223-1232.

12. IRIS. Integrated Risk Information System; U.S. Environmental Protection Agency: Washington, DC, USA, 1993.

13. Donaldson, J.; McGregor, D.; La Bella, F. Manganese neurotoxicity: A model for free radical mediated neurodegeneration? Can. J. Physiol. Pharmacol. 1982, 60, 1398-1405.

14. Subhash, M.N.; Padmashree, T.S. Regional distribution of dopamine B-hydroxylase and monamine oxidase in the brains of rats exposed to manganese. Food Chem. Toxicol. 1990, 28, 567-570.

15. Tran, T.; Crinella, F.M.; Chicz-Demet, A.; Lonnerdal, B.; Le, L.; Park, M. Effects of neonatal dietary in manganese exposure on brain dopamine levels and neurocognitive functions. Neurotoxicology 2002, 23, 645-651.

16. Gupta, S.K.; Murthy, R.C.; Chandra, S.V. Neuromelanin in manganese-exposed primates. Toxicol. Lett. 1980, 6, 17-20.

17. Eriksson, H.; Gillberg, P.G.; Aquilonious, S.M.; Headstrom, K.G.; Heilbronn, E. Receptor alterations in manganese intoxicated monkeys. Arch. Toxicol. 1992, 66, 369-364.

18. Cotzias, G.C. Manganese in health and disease. Physiol. Rev. 1958, 38, 503-532.

19. Pihl, R.O.; Parkes, M. Hair element content in learning disabled children. Science 1977, 198, 204-206.

20. Hafeman, D.; Factor-Litvak, P.; Cheng, Z.; van Green, A.; Ahsan, H. Association between manganese exposure through drinking water and infant mortality in Bangladesh. Environ. Health Perspect. 2007, 1157, 1107-1112.

21. Banta, R.G.; Markesbery, W.R. Elevated manganese levels associated with dementia and extrapyramidal signs. Neurology 1997, 27, 213-216.

22. Stredrick, D.L.; Stokes, A.H.; Worst, T.J.; Freeman, W.M.; Johnson, E.A.; Lash, L.H.; Aschner, M.; Vrana, K.E. Manganese-induced cytotoxicity in dopamine-producing cells. Neurotoxicology 2004, 25, 543-553.

23. Lloyd, R.V. Mechanism of the Manganese-Catalyzed Autoxidation of Dopamine. Chem. Res. Toxicol. 1995, 8, 111-116.

24. Chandra, S.V.; Shukla, G.S. Concentrations of striatal catecholamines in rats given manganese chloride through drinking water. J. Neurochem. 1981, 26, 683-687. 
25. Eriksson, K.; Magiste, K.; Plantin, L.O.; Fonnum, F.; Hedstrom, K.G.; Theodorsson, N.W.; Kristensson, K.; Stålberg, E.; Heilbronn, E. Effects of manganese oxide on monkeys as revealed by a combined neurochemical, histological and neurophysiological evaluation. Arch. Toxicol. 1987, 61, 46-52.

26. Lonnerdal, B. Manganese nutrition of infants. In Manganese in Health and Disease; Klimis-Tavantzis, D.J., Ed.; CRC Press: Boca Raton, FL, USA, 1994; pp. 175-191.

27. Stauber, J.L.; Florence, T.M.; Webster, W.S. The use of scalp hair to monitor manganese in the aborigines from Groote Eylandt. Neurotoxicology 1987, 8, 431-436.

28. Arnold, M.L.; McNeill, F.E.; Chettle, D.R. The feasibility of measuring manganese concentrations in human liver using neutron activation analysis. Neurotoxicology 1999, 20, 407-412.

29. Ericson, J.E.; Crinella, F.M.; Clarke-Stewart, K.A.; Allhusen, V.D.; Chan, T.; Robertson, R.T. Prenatal manganese levels linked to childhood behavioral disinhibition. Neurotoxicol. Teratol. 2007, 292, 181-187.

30. Gdula-Argasinska, J.; Sawicka-Kapusta, K.; Spence, B. Further investigation of the heavy metal content of the teeth of the bank vole as an exposure indicator of environmental pollution in Poland. Environ. Pollut. 2004, 131, 71-79.

31. Verney, C.N.; Zecevic, P.; Ezan, P. Expression of caalbindin D28K in the dopaminergic mesotelencephalic system in embryonic and fetal human brain. J. Comp. Neurol. 2001, 429, 45-58.

32. Malara, P.; Kwapulinkski, J.; Malara, B. Do the levels of selected metals differ significantly between the roots of carious and non-carious teeth? Sci. Total Environ. 2006, 369, 59-68.

33. Sharon, I.M. The significance of teeth in pollution detection. Perspect. Biol. Med. 1988, 32, 124-131.

34. Collip, P.J.; Chen, S.Y.; Maitinsky, S. Manganese in infant formulas and learning disability. Ann. Nutr. Metab. 1983, 27, 488-494.

35. Marlowe, M.; Bliss, L. Hair element concentrations and young children's behavior at school and home. J. Orthomol. Med. 1993, 9, 1-12.

36. Nowak, B.; Chmielnicka, J. Relationship of Lead and Cadmium to Essential Elements in Hair, Teeth, and Nails of Environmentally Exposed People. Ecotoxicol. Environ. Saf. 2000, 46, 265-274.

37. Abdullah, M.M.; Ly, A.R.; Goldberg, W.; Clark-Stewart, K.A.; Dudgeon, J.V.; Mull, C.G.; Chan, T.J.; Kent, E.E.; Mason, A.Z.; Ericson, J.E.J. Heavy metal in children's tooth enamel: Related to autism and disruptive behaviors? Autism Dev. Disord. 2012, 42, 929-936.

38. Mena, I. The role of manganese in human disease. Ann. Clin. Lab. Sci. 1974, 4, 487-491.

39. Fitsanakis, V.A.; Zhang, N.; Anderson, J.G.; Erikson, K.M.; Avison, M.J.; Gore, J.C.; Aschner, M. Measuring brain manganese and iron accumulation in rats following 14 weeks of low-dose manganese treatment using atomic absorption spectroscopy and magnetic resonance imaging. Toxicol. Sci. 2008, 103, 116-124.

40. Murphy, V.A.; Rosenberg, J.M.; Smith, Q.R.; Rapoport, S.I. Elevation of brain manganese in calcium deficient rats. Neurotoxicology 1991, 12, 255-264.

41. Lozoff, B.; Klien, N.K.; Nelsen, E.C.; McClish, D.K.; Manuel, M.K.; Chacon, M.E. Behavior of infants with iron deficiency anemia. Child Dev. 1998, 69, 24-36. 
42. Walter, T. Early and long-term effect of iron deficiency anemia on child development. In Nutritional Anemia: Nestle Nutritional Workshop Series; Foman, S.J., Zlotkin, S., Eds.; Raven Press: New York, NY, USA, 1992; Volume 30, pp. 81-90.

43. Rossander-Hulthen, L.; Brune, M.; Sandstrom, B.; Lonnerdal, B.; Hallberg, L. Competitive inhibition of iron absorption by manganese and zinc in Humans. Am. J. Clin. Nutr. 1991, $54,152-156$.

44. Davidson, L.; Cederblad, A.; Lonnerdal, B.; Sandstrom, B. The effect of individual dietary components on manganese absorption in man. Am. J. Clin. Nutr. 1992, 54, 1065-1070.

45. Keen, C.L.; Zidenberg-Cherr, S.; Lonnerdal, B. Nutritional and toxicological aspects of manganese intake. In Risk Assessment of Essential Elements Washington; Mertz, W., Abernathy, C.O., Olin, S.S., Eds.; ILSI Press: Washington, DC, USA, 1994; pp. 221-235.

46. Chandra, S.V.; Tandon, S.K. Enhanced manganese toxicity in iron-deficient rats. Environ. Physiol. Biochem. 1973, 3, 230-235.

47. Davis, C.D.; Malecki, E.A.; Greger, J.L. Interactions among dietary manganese, heme iron and non-heme iron in women. Am. J. Clin. Nutr. 1992, 56, 926-932.

48. Diez-Ewald, M.; Weintraub, L.R.; Crosby, W.H. Interrelationship of iron and manganese metabolism. Proc. Soc. Exp. Biol. Med. 1968, 129, 448-451.

49. Rehnberg, G.L.; Hein, J.F.; Carter, S.D.; Laskey, J.W. Age-dependent changes in gastrointestinal transport and retention of particulate manganese oxide in the rat. J. Toxicol. Environ. Health 1985, 16, 887-899.

50. Vega-Franco, L.; Robles-Martinez, B.; Mejia, A.M. Effect of iron deficiency on attention capacity among school children. Gac. Med. Mexico 1994, 130, 67-71.

51. Thomson, A.B.; Olatunbosun, D.; Valberg, L.S. Interrelation of intestinal transport system for manganese and iron. J. Lab. Clin. Med. 1971, 78, 642-655.

52. Aschner, M.; Aschner, J.L. Manganese neurotoxicity: Cellular effects and blood-brain barrier transport. Neurosci. Biobehav. Rev. 1991, 15, 333-340.

53. Yasui, M.; Ota, K.; Garruto, R.M. Effects of calcium-deficient diets on manganese deposition in the central nervous system and bones of rats. Neurotoxicology 1995, 16, 511-517.

54. Goyer, R.A. Lead toxicity: Current concerns. Environ. Health Perspect. 1993, 100, 177-187.

55. World Health Organization (WHO). International Program for Chemical Safety. In Inorganic Lead Environmental Criteria; Document 165; World Health Organization: Geneva, Switzerland, 1995.

56. American Psychiatric Association. Statistical Manual of Mental Disorders, Fourth Edition DSM-IV; American Psychiatric Association: Washington, DC, USA, 2001.

57. Pelham, W.E.; Gnagny, E.; Greenslade, K.E.; Milich, R. Teacher ratings of DSM-III-R symptoms for the disruptive behavior disorders. J. Am. Acad. Child Adolesc. Psychiatry 1992, 31, 210-218.

58. Lonnerdal, B.; Keen, C.L.; Ohtake, M.; Tamura, T. Iron, zinc, copper and manganese in infant formulas. Am. J. Dis. Child. 1983, 137, 433-437.

59. Woolf, A.D.; Bellinger, D.C.; Wright, R.O. Environmental Manganese Exposures: A Risk to Children's Health? Clin. Toxicol. 2007, 45, doi:10.1080/15563650701284894.

60. Konofal, E.; Lecendreux, M.; Arnulf, I.; Mouren, M.C. Iron deficiency in Children with Attention-Deficit/Hyperactivity Disorder. Arch. Pediatr. Adolesc. Med. 2004, 158, 1113-1115. 
61. Sever, Y.; Ashkenazi, A.; Tyano, S.; Weizman, A. Iron treatment in children with Attention Deficit Hyperactivity Disorder. Neuropsychobiology 1997, 354, 178-180.

62. Kordas, K.; Stoltzfus, R.J.; Lopez, P.; Rico, J.; Rosado, J.L. Iron and zinc supplementation does not improve parent or teacher ratings of behavior in first grade Mexican children exposed to lead. J. Pediatr. 2005, 1475, 632-639.

63. Bonjour, J.P.; Carrie, A.L.; Ferrari, S.; Clavien, H.; Slosman, D.; Theintz, G.; Rizzoli, R. Calcium-enriched foods and bone mass growth in prepubertal girls: A randomized, double-blind, placebo-controlled trial. J. Clin. Investig. 1997, 99, 1287-1294.

64. Black, R.E.; Williams, S.M.; Jones, I.E.; Goulding, A. Children who avoid drinking cow milk have low dietary calcium intakes and poor bone health. Am. J. Clin. Nutr. 2002, 76, 675-680.

65. Cashman, K.D. Calcium intake, calcium bioavailability and bone health. Br. J. Nutr. 2002, 87, S169-S177.

66. Flynn, A. The role of dietary calcium in bone health. Proct. Nutr. Soc. 2003, 62, 851-858.

67. Sallee, F.R.; Sethuraman, G.; Rock, C.M. Effects of pimozide on cognition in children with Tourette syndrome: Interaction with comorbid attention deficit hyperacitivity disorder. Acta Pyschiatr. Scand. 1994, 90, 4-9.

68. Starobrat-Hermelin, B. The effect of selected bioelements on hyperactivity in children with certain specified mental disorders. Ann. Acad. Med. Stetin. 1998, 44, 297-314.

69. Gunier, R.B.; Mora, A.M.; Smith, D.; Arora, M.; Austin, C.; Eskenazi, B.; Bradman, A. Biomarkers of manganese exposure in pregnant women and children living in an agricultural community in California. Environ. Sci. Technol. 2014, 48, 14695-14702.

70. Gunier, R.B.; Bradman, A.; Jerrett, M.; Smith, D.R.; Harley, K.G.; Austin, C.; Vedar, M.; Arora, M.; Eskenazi, B. Determinants of Manganese in Prenatal Dentin of Shed Teeth from CHAMACOS Children Living in an Agricultural Community. Environ. Sci. Technol. 2013, 47, 11249-11257.

(C) 2015 by the authors; licensee MDPI, Basel, Switzerland. This article is an open access article distributed under the terms and conditions of the Creative Commons Attribution license (http://creativecommons.org/licenses/by/4.0/). 